\title{
A LABORATORY AND FIELD STUDY ON 2DH SPECTRAL WAVE TRANSFORMATION IN MUDDY ENVIRONMENTS
}

\author{
Mohsen Soltanpour ${ }^{1}$, S. Abbas Haghshenas ${ }^{2}$ and Tomoya Shibayama ${ }^{3}$ \\ The present paper offers a set of wave basin experiments on muddy beds together with field measurements data at \\ Hendijan Mud Coast in the north-west corner of the Persian Gulf in order to investigate the 2DH spectral wave \\ transformation over muddy beds. A dissipation model was added to REF/DIF S wave model to develop a numerical \\ wave spectrum transformation model for muddy beaches. The proposed model was utilized to analyze the \\ experimental and field measurements data on muddy beds. The simulated wave spectra over-mud bed are in fair \\ agreement with the measurements.
}

Keywords: wave attenuation; fluid mud; visco-elastic model; wave-mud interaction; wave transformation

\section{INTRODUCTION}

A prerequisite for the reliable estimation of waves on maritime structures is a detailed understanding of how waves transform during their propagation (Goda, 2000). Considerable decay of wave energy along the wave trajectory over muddy beds makes a different wave transformation in comparison to sandy environments. Literature shows that the role of soft mud to dissipative waves has been investigated through modeling and laboratory experiments by many researchers (e.g., Sakakiyama and Bijker, 1989; Ross and Mehta, 1990; and de Boer et al., 2009).

The present study offers two sets of data for interacting waves with soft muddy beds; one is a large set of wave basin experiments on a general three dimensional bathymetry under both regular and irregular waves, and the other one is a one-month period of field measurements at two stations (offshore and nearshore) in Hendijan mud coast on the Iranian coastline of the north-west part of the Persian Gulf. They have been utilized in a two dimensional numerical model for better understanding of the complex spectral wave transformation on conditions where the combined effects of shoaling, refraction and diffraction as well as the wave energy dissipations due to mud bed existence and wave breaking exist.

\section{LABORATORY EXPERIMENTS}

Wave basin experiments were carried out at the hydraulic laboratory of Yokohama National University. The basin was measured $10.5 \mathrm{~m}$ in length by $9.0 \mathrm{~m}$ wide with a bottom slope of 1:30. Figure 1 shows the top view of the wave basin. An iron plate with mild 1:3 to 1:2 slopes was put on the front edge of mud box to eliminate the sudden vertical change of bottom level and fine gravels were employed in the three other sides. A 1:4 slope made of gravel materials was also put at the end of the wave basin to reduce the amount of reflected waves.

Commercial kaolinite was used to prepare the fluid mud bed. Mud sample was put in a box in the wave basin measured $2.7 \mathrm{~m}$ in both directions and $10 \mathrm{~cm}$ in height. Regular and irregular waves were generated by the wave paddles at the edge of the basin. The horizontal pre-prepared kaolinite bed was subjected to constant wave action in a water depth of 16 to $18 \mathrm{~cm}$ over the mud surface for the duration of $300 \mathrm{~s}$. The characteristics of incident wave approaching the mud section and the waves at five points over the mud box were recorded. Figure 2 shows the experimental setup.

\footnotetext{
${ }^{1}$ Dept. Civil Eng., K.N. Toosi University of Technology, No.1346, Vali-Asr St., P.C. 1996715433, Tehran, IRAN, Email: soltanpour@kntu.ac.ir

${ }^{2}$ Dept. Civil Eng., K.N. Toosi University of Technology, No.1346, Vali-Asr St., P.C. 1996715433, Tehran, IRAN, Email: sahaghshenas@dena.kntu.ac.ir

${ }^{3}$ Dept. Civil Eng., Yokohama National University, 79-5 Tokiwadai, Hodogaya-ku, Yokohama, Japan 240-8501, Email: tomo@ynu.ac.jp
} 


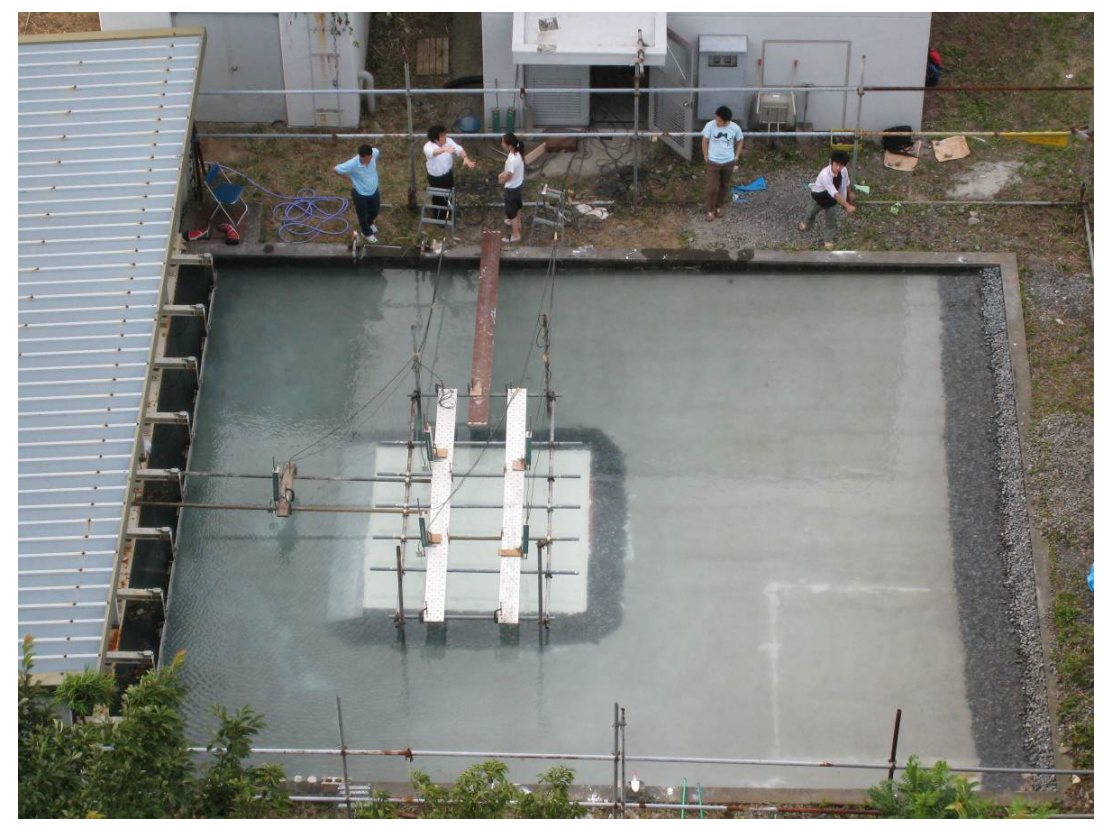

Figure 1. Top view of wave basin and mud box.

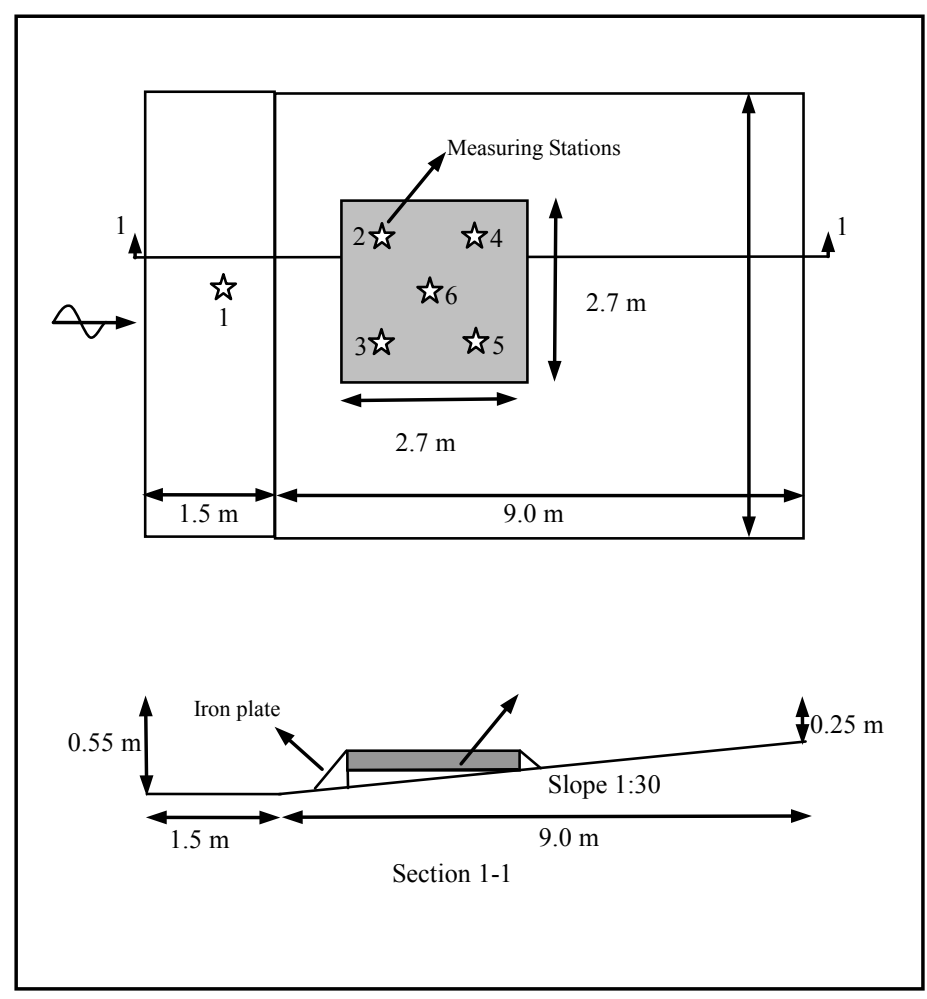

Figure 2. Experimental setup sketch.

\section{FIELD MEASUREMENTS}

Northwest part of the Persian Gulf is covered with mud originated mainly from Arvand River catchment area. Mud deposits up to 20 meters thickness is observed at the very shallow coast of Hendijan Fishery Port (Figure 3). A set of field measurements was performed at the field site from 20th of February to 28th of March, 2007. Directional wave spectra and vertical current velocity profiles were simultaneously recorded at two stations, i.e. nearshore (2.5 $\mathrm{m}$ deep) and offshore (10 $\mathrm{m}$ deep). 
Mud samples from the top 1-meter layer were also collected to define mud characteristics at different points of the coast including rheological properties and mud densities. The largest wave event occurred during 15-16 March 2007 with significant wave heights of $1.39 \mathrm{~m}$ and $1.04 \mathrm{~m}$ at offshore and nearshore stations, respectively.

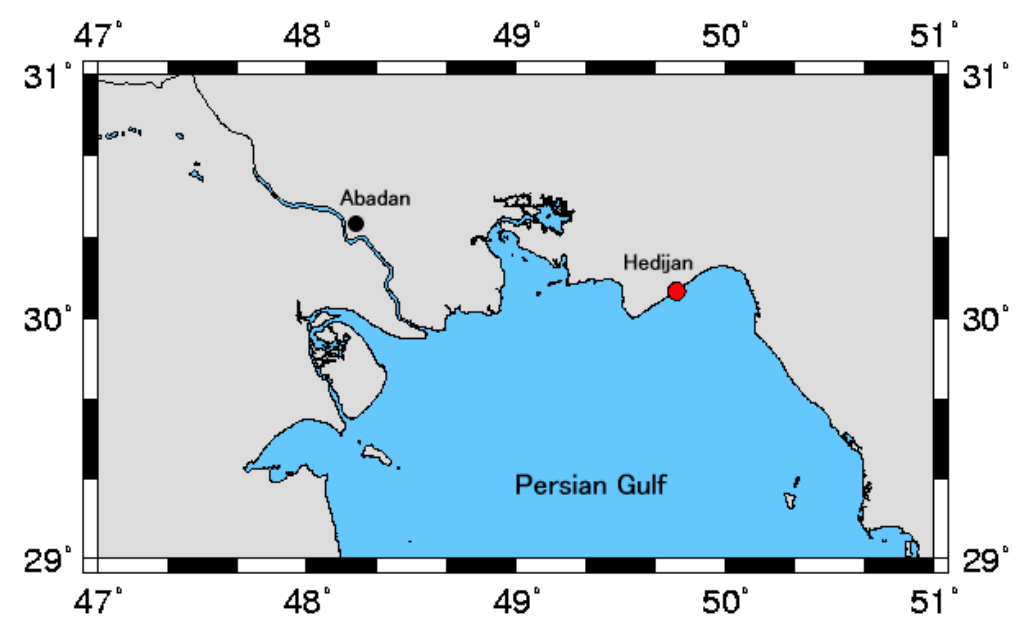

Figure 3. Location of Hendijan Fishery Port at North West of the Persian Gulf.

\section{NUMERICAL MODEL}

The REF/DIF S wave model is employed in the present study to simulate spectral wave propagation over the physical model domain and also Hendijan muddy coast. Assuming viscoelastic rheological behavior for the fluid mud, a multi layered fluid system is employed to simulate wave attenuation rate. The viscoelastic parameters were derived from independent rheological tests on commercial kaolinite and natural Hendijan mud using an Anton Paar Physica MCR300 instrument. The calculated values of the energy dissipation rates in the area covered by fluid mud are finally introduced to REF/DIF S wave transformation model to simulate wave propagation over the muddy beds.

\section{RESULTS AND DISCUSSION}

Modified version of REF/DIF S wave model including dissipation effects due to mud bed existence are employed to simulate the complex 2D irregular wave-fluid mud interaction. Introducing incident wave spectrum to the numerical model, Figure 4 illustrates an example of the measured and simulated irregular wave spectra at all six stations of wave basin. The measured spectrum at the mud box centre is double-peaked that reveals that wave transformation over the box is highly affected by wave refraction from the sides. Figure 5 presents measured wave spectra in both stations at Hendijan mud coast together with the simulated wave spectrum in the nearshore station through REF/DIF S modified model. It is observed that the measured and simulated wave spectra in both laboratory and field cases show fair agreements.

\section{SUMMARY AND CONCLUSION}

The summary and main conclusions of the present study are as follows

- A coupled 2D wave transformation model was developed which combines the mud induced wave dissipation with shallow water processes.

- Irregular effects of waves were included in both modeling and experimental/field survey investigations.

- Application of the numerical model to simulate wave basin experiments and field data shows reasonable agreement. 


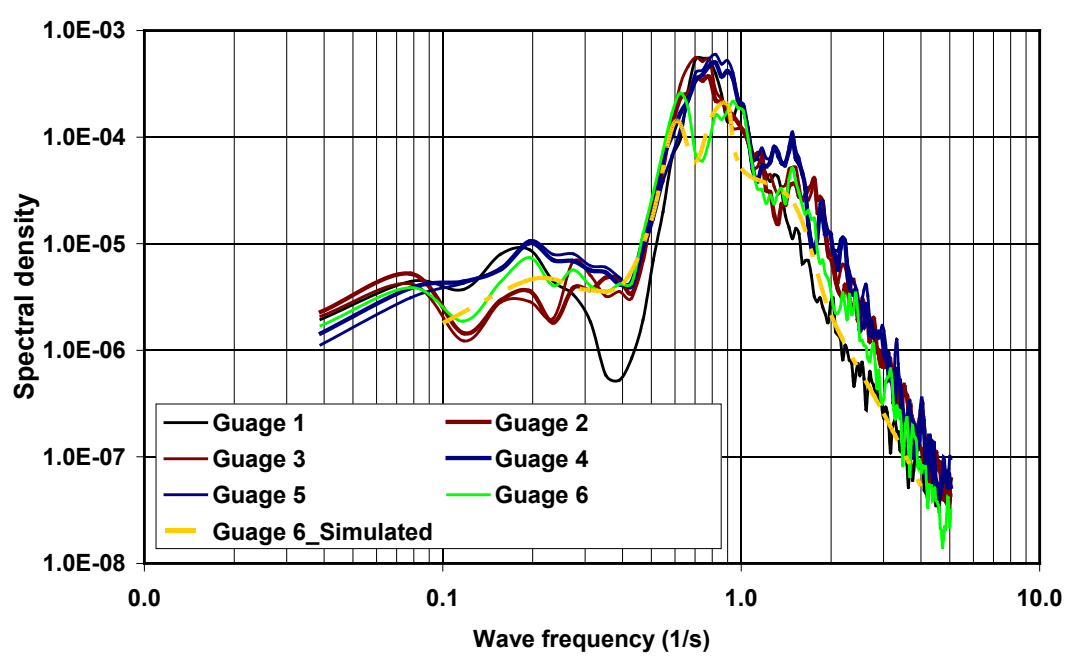

Figure 4. Measured and simulated wave spectra, wave basin case.

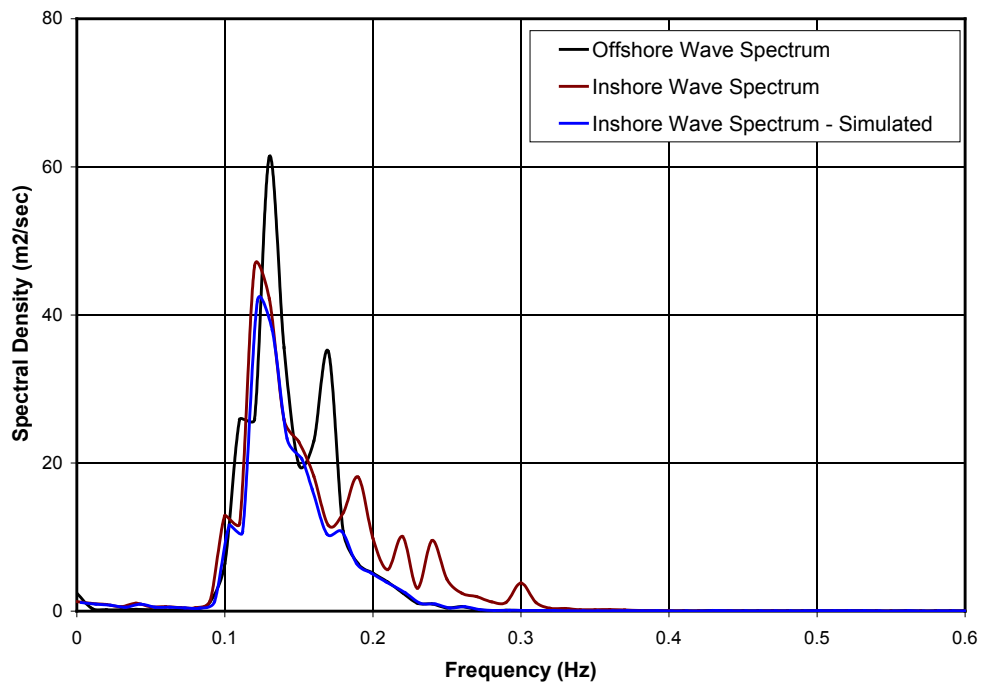

Figure 5. Measured and simulated wave spectra, Hendijan mud coast case.

\section{REFERNCES}

de Boer, G.J., Winterwerp, J.C., and van Dongeren, Ap., 2009. Flume experiments of wave damping by fluid mud. Proc. of INTERCOH 2009, Brazil.

Goda, Y., 2000. Random seas and design of maritime structures. World Scientific Publishing Co., 443p. Ross, M. A., Mehta, A. J., 1990. Fluidization of soft estuarine mud by waves. In: The Microstructure of Fine Grained Sediments: From Mud to Shale, R. H. Bennett ed., Springer-Verlag, New York, pp. 185-191.

Sakakiyama, T., Bijker, E. W., 1989. Mass transport velocity in mud layer due to progressive waves. Journal of Waterway, Port, Coastal and Ocean Engineering, ASCE, Vol. 115, No. 5, pp. 614-633. 